\title{
A STUDY ON THE ECOTOURISM COGNITION AND ITS FACTORS
}

\author{
TAI, Y.-N. \\ Department of Tourism, I-Shou University, Taiwan \\ No.1, Sec. 1, Syuecheng Rd., Dashu District, Kaohsiung City, Taiwan, R. O. C. \\ e-mail:dennistai1217@gmail.com \\ (Received $12^{\text {th }}$ Aug 2016; accepted $15^{\text {th }}$ Nov 2016)
}

\begin{abstract}
Due to the practice of two-day weekend, the public gradually emphasize the demand for tourism, and ecotourism becomes the best leisure and entertainment activity. Taking the development of ecotourism as the center of tourism and recreation, ecotourism activity would cause certain degree of impact on the environment, when paying attention to the quality of leisure life. In this case, changes in ecology would appear negative impact on the environment. Aiming at Tianmen Mountain Ecological Tourism Scenic Spot, the visitors, as the research subjects in this study, are distributed 300 copies of questionnaire. A total of 224 valid copies are retrieved, with the retrieval rate $75 \%$. The research results are summarized as following. 1. Ecotourism cognition presents significantly positive effects on environmental attitudes. 2. Environmental attitudes show remarkably positive effects on environmental impact. 3. Ecotourism cognition reveals notably positive effects on environmental impact. Suggestions, based on the results, are proposed in this study, expecting to develop ecotourism as well as reduce the impact on the environment.
\end{abstract}

Keywords: environmental awareness, environmental impact, environmental attitudes, citizen participation, social

\section{Introduction}

The advance of high technology has constantly enhanced the quality of human life, and the public gradually emphasize the demand for tourism. Nevertheless, in face of the continuous occurrence of major natural disasters in recent years, the utilization of natural resources therefore should stress on safety. In addition to the development of technology industry and the promotion of national income, leisure, tourism, and travel have become a part of human life. Ecotourism, with the function of ecological education, focuses on deep experience in the unique nature and culture as well as the natural ecology. When the quality of leisure life is emphasized, ecotourism activity would still impact the environment to some degree to change the ecology and even appear negative impact on the environment.

The practice of two-day weekend has ecotourism become the best leisure and entertainment activity for the citizens. Taking ecotourism as the core of tourism and recreation, the impact on the environment would be relatively enhanced. By understanding the environmental impact caused by tourism activity and reducing the impact with management strategies, the environmental impact resulted from ecotourism activity would be more positive. The past recreation activity concentrated on developed scenic recreation areas with lower local environmental sensitivity than natural areas. Nonetheless, the higher use frequency, the management attitudes, site development, and visitor behaviors could result in the stress on the environment. The recreation environment therefore reveals over carrying capacity. Ecotourism, integrating 
environmental awareness into recreation behaviors, could achieve the purpose of instruction through entertainment. It is a key development direction for domestic and international environment conservation and tourism development. As a matter of fact, the key lies in the public sense of mission to protect the environment. Visitors have to deeply understand the value of environmental heritage and the responsibility for the environment. People have no right to advance the tourism and recreation treasure. Tourism activity could really be sustainably developed merely by insisting on the definition and principles of ecotourism; especially, tourism policies have been emphasized in advanced and developed countries.

\section{Literature review and hypothesis}

\section{Ecotourism cognition}

Mair (2011) regarded ecotourism, based on natural resources, as the historical and geographic heritage of human beings, the environmental protection and environmental education, and the regional profits achieving the objective goal and the sustainable development. Coghlan (2012) considered ecotourism as nature and culture oriented tourism. Lee (2011) pointed out ecotourism as a travel pattern initially based on local natural history and inherent culture. Ecotourists, when visiting an undeveloped area based on the spirits of appreciation, participation, and perception, would not appear expendable damage on wild creatures and natural resources in the tourism process, but contribute to the living economy of local citizens through employment or other economic tactics. Local governments regard ecotourism as a management method to acquire funds for establishing or developing the area and communities through business management. The cognitive component contains direct experience or information acquired from various channels to form knowledge and perception for the subject matter of attitudes. Such knowledge and the generated perception form the so-called beliefs, representing that consumers believe in certain attributes and characteristics of such subject matter and special results generated by different behaviors (McKercher et al., 2010). Neuhofer et al. (2012) defined cognition as the psychological process to know and comprehend affairs. The result of the cognition process is belief, which is defined as the cognition evaluation of affairs according to specific attributes or characteristics. Cognition is the temporary understanding, knowing, and opinions of a person to people or affairs (Phillips et al., 2013). Lu and Stepchenkova (2012) defined "cognition", with general explanations, as all forms of knowing, including feeling, memory, inference, perception, plan, notice, imagination, expectation, decision, problem-solving, and thought communication to further discuss the ecotourism cognition of visitors. Regarding the promotion of tribal ecotourism by Maori in New Zealand, Puhakka (2011) indicated that allowing the cognition and participation of citizens could have them show the participation intention in ecotourism, including "economic dimension", "psychological dimension", "social dimension", and "political dimension". Referring to Han et al. (2011), "environmental awareness", "citizen participation", "economic feedback", and "public funds" deducted from the factor analysis of citizens' ecotourism cognition and attitudes are used as the ecotourism cognition dimensions in this study. 


\section{Environmental attitudes}

Generally speaking, attitudes are the result of cognition and learning process, responding to the feeling or opinions to like or dislike certain affairs (Eijgelaar and de Kinderen, 2014). Attitudes also refer to an individual, towards people, affairs, objects, and surrounding world, presenting a lasting and consistent behavior intention depending on the cognition and preference (Kang et al., 2012). Currently, the commonest definition of attitudes combines the elements of cognitive theory and learning theory. That is, the attitudes towards any affairs, concepts, or people are a lasting orientation towards such people, affairs, objects, or concepts based on cognition, affection, and behaviors (Andrades-Caldito et al., 2013). The environmental attitudes in this study are referred to Huang (2012) that humans form the attitudes towards specific people, affairs, and objects through cognition, affection, and behaviors. Such components of attitudes are explained as below (Gössling, 2011):

\section{(1) Cognitive component}

It refers to individual cognition of the attitude object, including the fact, knowledge, and belief of such an object. It is the belief, evaluation, or opinions about people or affairs. "Cognition" is personal understanding, knowing, and opinions about an "attitude object" (Heimlich and Ardoin, 2012). Cognition covers broad meanings, including the complicated psychological activity of perception, imagination, identification, reasoning, and judgment (Mobley et al., 2010).

(2) Affective component

It contains individual evaluation of the feeling, emotion, or concern about the object. In other words, affective component is a part of emotion or affection, which would generate with concepts, including feeling and emotion, i.e. the preference and disgust at the attitude object (Shrode, 2012). It could be individual positive and negative emotion judgment of certain objects doing good or bad (Lawrence, 2012).

(3) Behavior component

It refers to individual reaction or behavior intention to the object, i.e. the preparation of behaviors. It is the potential power and preparation state of agreeing or disagreeing with certain objects, people, or situations (Trochidis and Bigand, 2015). It could also be the inner process of an individual consciously, purposively, and in a planned way approaching the pursued goal (Robeia et al., 2011).

\section{Environmental impact}

De Ávila (2011) defined impact as the change and effect, or new conditions resulted from certain activity or a series of relevant events, which existed in double-edged, i.e. positive profit impact and negative impact. Tourism activity would result in impact on local economy, social culture, and environments. The effect of tourism on economy has been broadly studied. Early research stressed more on positive economic benefits, but ignored the impact of tourism on local economy. Tourism is rapidly developed in the world as people agree with the advantage of tourism for economic prosperity (Fielding and Head, 2012). The boom of tourism industry reveals that more and more countries and regions would be impacted by the growth of tourism. It is broadly agreed that recreational areas present distinct capacity of tourists in accordance with time and location. When the number of tourists is restricted under the extreme level and the 
economic influence is positive, the appearance of tourists would be accepted and welcomed by most citizens. Once the number is over the limit, a lot of negative effects would result in the citizens' dissatisfaction to appear xenophobic thoughts and behaviors (Nishiyama and Terasawa, 2013). Regardless of the positive or negative impact of tourism, Young, Pizam, Ryan, Mathieson, and Wall classified tourism impact into economic impact, social and cultural impact, and physical environment impact (Kim et al., 2011).

Referring to Choi and Ritchie (2014), three levels of the ecotourism impact on the environment are applied to this study.

(1) Environment level: When visitors are not controlled and limited, they would no doubt destroy the environment. The prevalence period of ecotourism is normally the important season for animals and plants maintaining the species survival. Visitors are lack of information about the carrying capacity of the destinations that ecotourism exists damage in the environment.

(2) Economic level: Most ecotourists come from the northern hemisphere with travel agents handling the tours that local medium and small enterprises could not develop, economic profits return to advanced countries, and local citizens cannot make profits.

(3) Social and cultural level: Local citizens could merely receive few profits from visitors, and even are regarded as a tourism product. Visitors cause impact on local culture, and the youth learn foreign culture but ignore to pass down traditional culture.

\section{Research hypothesis}

Lawrence (2012) found out the positive correlation between citizen supports with tourism and perceived positive effects as well as the negative correlation with perceived negative effects. Trochidis and Bigand (2015) regarded environmental attitudes as individual supports with environmental affairs. Wang (2010) discovered that local citizens would tend to increase tourism limitations and tax when they perceived negative tourism impact. Neuhofer et al. (2012) indicated that observable and judgable attitudes could be formed merely when cognition, affection, and behavioral intention were taken into account. "Cognition" was related to knowing and understanding the relationship between expression situations and attitude objects, which belonged to thoughts or reason. "Affection" was related to emotions accompanied with ideas or topics, including individual emotional judgment of people, affairs, and objects. "Behavioral intention" was related to the pre-arrangement or preparation of behaviors, containing individual reaction or reaction to people, affairs, and objects. Accordingly, the following hypothesis is proposed in this study.

H1: Ecotourism cognition presents significantly positive effects on environmental attitudes.

Coghlan (2012) regarded environmental attitudes as the lasting and consistent psychological state of an individual about the problems related to the environment, i.e. individual environmental attitudes. Environmental attitudes therefore were the lasting psychology state of an individual about environmental cognition and the preference. Nishiyama and Terasawa (2013) pointed out environmental attitudes as the gather of beliefs which would affect individual activity related to environmental issues or keep 
the behavioral intention. In other words, environmental attitudes were the important reference to consumer concerns for psychological health and environment. De Ávila (2011) studied human actions on protecting or preserving the environment. Puhakka (2011) indicated that attitudes could be the predictive variable of behavioral intention, when selecting tourism, to explain the diversity of personal behaviors. The following hypothesis is therefore proposed in this study.

H2: Environmental attitudes show remarkably positive effects on environmental impact.

Huang (2012) considered that ecotourism appeared the minimum environmental impact on the destinations but could contribute to the resource conservation for environmental protection; besides, facilitating the exchange and understanding between visitors and local citizens could enhance local economic benefits, social welfare, and employment opportunities. Taking ecotourism cognition as an independent variable and environmental impact sensitivity as a dependent variable and having environmental attitudes, location, and cultural difference as the harmonic variables, Lee (2011) revealed that ecotourism cognition would affect environmental impact sensitivity, and distinct environmental attitudes, location, and culture would also influence visitors' environmental impact sensitivity. Mobley et al. (2010) mentioned that ecotourism developed the maximum benefits with local knowledge and culture and, under the minimum environmental impact, provided the maximum satisfaction for visitors. Kim et al. (2011) pointed out the negative environmental impact of tourism on developing countries developing potential products to change the ecological resources of animals and plants in destinations. Han et al. (2011) proposed a series of negative impact caused by ecotourism activity in protected areas, including overcrowding, over development, unregulated recreation activity, pollution, wild species, and the use of powered vehicles. As a result, the following hypothesis is proposed in this study.

H3: Ecotourism cognition reveals notably positive effects on environmental impact.

\section{Sample and measurement indicator}

\section{Research sample and object}

Tianmen Mountain Ecological Tourism Scenic Spot, located in Yongtai County, Fujian Province, Ge Zhen Creek Yeung, with the area of 6 square kilometers and the highest elevation of 828 meters, is named "Tianmen Mountain" because of a huge stone shaped like a door. Tianmen Mountain Ecological Tourism Scenic Spot connects with the routes of Tianmen Cave Scenic Group and Wanxi Canyon, with total 7 kilometers long, along which there is astonishing natural appearance. Tianmen Cave Scenic Group covers natural landscapes of Tianmen Cave, Guanyin Cave, Sun-Moon Cave, Tian Cliff, and Tian Bridge. It is worth mentioning that there is a novel finding by looking at the rocks above the underground river. Over ten-thousand-year stalactites naturally grow the shapes of Guanyin and Maitreya. Such natural creations are local wonders. The underground rive in Tianmen Cave Scenic Group and the special "pearls poured from a gourd" have been appraised as first-class touring spots. Tianmen Mountain Ecological Tourism Scenic Spot is therefore selected for this study, and the visitors, as the research subjects, are distributed 300 copies of questionnaire. Total 224 valid copies are retrieved, with the retrieval rate $75 \%$. 


\section{Test of reliability and validity}

Validity refers to the measuring tool being able to really measure the questions which a researcher intends to measure. Validity is generally divided into content validity, criterion-related validity, and construct validity. The questions in this study are referred to domestic and international research, and a pretest is preceded after discussing with the tutor that this questionnaire presents certain content validity. The entire structure causal relationship of ecotourism cognition, environmental attitudes, and environmental impact are tested with Linear Structural Relations Model, and the data input is based on the correlation coefficient matrix of above observation variables. The analysis results with Linear Structural Relations Model reveal the reasonable range of the overall model fit that it presents favorable convergent validity and predictive validity. According to Kerlinger (1986), the construct validity of a questionnaire could be tested with item-to-total correlation coefficient, i.e. reliability analysis. The acquired item-to-total correlation coefficient could be used for judging the questionnaire content. The item-to-total correlation coefficients of the dimensions in this study are above 0.6, showing certain degree of construct validity of the dimensions in the questionnaire.

To further understand the reliability and validity, both reliability and validity analyses are preceded. According to Guilford (1965), the higher Cronbach's $\alpha$ reveals the better reliability. The formal questionnaire in this study is developed based on the standard, and the measured Cronbach's $\alpha$ reliability coefficient appears in 0.80 0.90, conforming to the reliability range.

\section{Analysis of experimental result}

\section{Evaluation indicator of LISREL model}

LISREL model (linear structural relation), combining Factor Analysis and Path Analysis in traditional statistics and including simultaneous equations in econometrics, could simultaneously calculate multi-factor and multi-causal path. Regarding the evaluation of goodness-of-fit of a model, Bagozzi and Yi (1998) proposed to evaluate the preliminary fit criteria, overall model fit, and fit of internal structural of model. The research data are organized in Table 1 . The preliminary fit criteria, internal goodness-of-fit and overall model fit of the model are explained as following.

From the analysis of the entire model in Table 1, the explanation of the four dimensions (environmental awareness, citizen participation, economic feedback, public fund) in ecotourism cognition to ecotourism cognition achieves the significance ( $t>1.96$, $\mathrm{p}<0.05$ ); the explanation of the three dimensions (cognitive component, affective component, behavior component) in environmental attitudes to environmental attitudes reaches the significance $(\mathrm{t}>1.96, \mathrm{p}<0.05)$; and, the explanation of the three dimensions (environmental level, economic level, social and cultural level) in environmental impact to environmental impact achieves the significance $(\mathrm{t}>1.96, \mathrm{p}<0.05)$. Apparently, the overall model shows favorable preliminary fit criteria.

In regard to the internal goodness-of-fit, ecotourism cognition and environmental attitudes $(0.863, \mathrm{p}<0.01)$ present positive and significant correlations, environmental attitudes and environmental impact $(0.871, \mathrm{p}<0.01)$ shows positive and remarkable correlations, and ecotourism cognition and environmental impact $(0.886, \mathrm{p}<0.01)$ also reveal positive and notable correlations. $\mathrm{H} 1, \mathrm{H} 2$, and $\mathrm{H} 3$ are therefore supported. 
Regarding the overall model fit, the standards $\chi 2 / \mathrm{Df}=1.751$, lower than the standard 3 , and $\mathrm{RMR}=0.006$ show that both $\chi 2 / \mathrm{DF}$ and $\mathrm{RMR}$ are appropriate. Furthermore, chi-square value is sensitive to sample size that it is not suitable for directly judging the goodness-of-fit. However, the standards GFI=0.969 and AGFI $=0.921$ are higher than the standard 0.9 (the closer GFI and AGFI to 1, the better goodness-of-fit of the model) that this model presents better goodness-of-fit indicators.

Table 1. Analysis of LISREL model

\begin{tabular}{|c|c|c|c|c|}
\hline $\begin{array}{l}\text { Evaluation } \\
\text { item }\end{array}$ & \multicolumn{2}{|c|}{ Parameter/evaluation standard } & Result & $\mathrm{t}$ \\
\hline \multirow{10}{*}{$\begin{array}{l}\text { Preliminary fit } \\
\text { criteria }\end{array}$} & \multirow{4}{*}{$\begin{array}{l}\text { Ecotourism } \\
\text { cognition }\end{array}$} & $\begin{array}{l}\text { Environmental } \\
\text { awareness }\end{array}$ & 0.741 & $8.33 * *$ \\
\hline & & $\begin{array}{c}\text { Citizen } \\
\text { participation }\end{array}$ & 0.755 & $8.45^{* *}$ \\
\hline & & $\begin{array}{l}\text { Economic } \\
\text { feedback }\end{array}$ & 0.738 & $7.69 * *$ \\
\hline & & public fund & 0.691 & $6.42 * *$ \\
\hline & \multirow{3}{*}{$\begin{array}{l}\text { Environmental } \\
\text { attitudes }\end{array}$} & $\begin{array}{l}\text { Cognitive } \\
\text { component) }\end{array}$ & 0.682 & $6.37 * *$ \\
\hline & & $\begin{array}{l}\text { Affective } \\
\text { component }\end{array}$ & 0.705 & $8.16^{* *}$ \\
\hline & & $\begin{array}{l}\text { Behavior } \\
\text { component }\end{array}$ & 0.713 & $8.21 * *$ \\
\hline & \multirow{3}{*}{$\begin{array}{l}\text { Environmental } \\
\text { impact }\end{array}$} & $\begin{array}{c}\text { Environmental } \\
\text { level }\end{array}$ & 0.813 & $10.66^{* *}$ \\
\hline & & Economic level & 0.802 & $9.47 * *$ \\
\hline & & $\begin{array}{c}\text { Social and } \\
\text { Cultural level }\end{array}$ & 0.804 & $9.52 * *$ \\
\hline \multirow{3}{*}{$\begin{array}{l}\text { Internal } \\
\text { goodness-of-fit }\end{array}$} & \multicolumn{2}{|c|}{$\begin{array}{c}\text { Ecotourism } \\
\text { cognition } \rightarrow \text { environmental attitudes }\end{array}$} & 0.863 & $18.73 * *$ \\
\hline & \multicolumn{2}{|c|}{$\begin{array}{c}\text { Environmental } \\
\text { attitudes } \rightarrow \text { environmental impact }\end{array}$} & 0.871 & $22.45^{* *}$ \\
\hline & \multicolumn{2}{|c|}{$\begin{array}{c}\text { Ecotourism } \\
\text { cognition } \rightarrow \text { environmental impact }\end{array}$} & 0.886 & $27.64 * *$ \\
\hline \multirow{4}{*}{$\begin{array}{l}\text { Overall model } \\
\quad \text { fit }\end{array}$} & \multicolumn{2}{|c|}{$\mathrm{X} 2 / \mathrm{Df}$} & \multicolumn{2}{|c|}{1.751} \\
\hline & \multicolumn{2}{|c|}{ GFI } & \multicolumn{2}{|c|}{0.969} \\
\hline & \multicolumn{2}{|c|}{ AGFI } & \multicolumn{2}{|c|}{0.921} \\
\hline & \multicolumn{2}{|c|}{ RMR } & \multicolumn{2}{|c|}{0.006} \\
\hline
\end{tabular}

Note: * stands for $\mathrm{p}<0.05, * *$ for $\mathrm{p}<0.01$, and $* * *$ for $\mathrm{p}<0.001$

\section{Conclusion}

The research results reveal the positive and significant effects of ecotourism cognition on environmental attitudes and environmental impact that ecotourists show higher concerns about the environment. Visitors with responsible environmental 
attitudes would not make noise when finding exotic flowers and plants and directly touch fish, animals, and plants in the ecotourism process. The respect for and protection of the environment conform to the model of ecological sustainable development. In terms of the selection between environment sustainability and economic development, ecotourism appears positive effects on citizens by enhancing employment opportunities and improving public construction. The correlation between ecotourism and environmental impact therefore needs to be clarified. It would also impacts physical environment, economy, society, and culture. Moreover, "ecotourism cognition" indirectly affects "environmental impact" that visitors with better understanding of ecotourism cognition would perceive stronger impact on the environment and visitors with better understanding of ecotourism would enhance the environmental sensitivity. Regardless the citizen cognition of environmental impact, tourism activity in national parks could provide visitors with environmental education and enhance the environment cognition and ecological conservation to concern more about local communities.

\section{Suggestion}

Aiming at the research results and findings, practical suggestions are further proposed in this study.

1. Visitors could bring profits in tourism areas, and each tourism area expects and dreams of more visitors. Local governments therefore are suggested to carefully use the resources to promote the spirit of ecotourism from "natural attraction and sustainable management", excite visitors to visit ecotourism parks to increase local income, invite visitors joining in the ecology protection, and improve the environmental impact of visitors on ecotourism parks.

2. Establishing definite visitor centers allows visitors easily acquiring information about ecotourism parks. The introduction with DM or the visitor center personnel with systematical and complete promotion of ecotourism parks could have visitors clearly realize the characteristics of ecotourism parks and the correct position, rather than too many visitors crowding the same place and concentrating rubbish. Such a method could effectively separate visitors' routes and indirectly reduce the environment impact of visitors on ecotourism parks.

3. The government is suggested to establish the feedback mechanism when developing the environment-protection ecotourism, including the increase of income and employment opportunities of local citizens. For example, visitors are offered to apply for environment or history interpreters, and local citizens have the priority in serving as interpreters and environment administrators to guarantee the employment opportunities and rights. Such conduct could educate visitors, protect the natural environment in ecotourism and the welfare of citizens, as well as enhance visitor s' intention to visit and recommendation behaviors.

\section{REFERENCE}

[1] Andrades-Caldito, L., Sánchez-Rivero, M., Pulido-Fernández, J. I. (2013): Differentiating Competitiveness through Tourism Image Assessment: An Application to Andalusia(Spain). - Journal of Travel Research 52: 68-81. 
[2] Bagozzi, R. P., Yi, Y. (1988): On the Evaluation of Structure Equations Models. - Journal of Academy of Marking Science 16(1): 74-94.

doi: 10.1007/BF02723327

[3] Choi, A. S., Ritchie, B. W. (2014): Willingness to pay for flying carbon neutral in Australia: an exploratory study of offsetter profiles. - Journal of Sustainable Tourism 22(8): 1236-1256. doi:10.1080/09669582.2014.894518

[4] Coghlan, A. (2012): Linking natural resource management to tourist satisfaction: a study of Australia Great Barrier Reef. - Journal of Sustainable Tourism 20: 41-58.

[5] de Ávila, A. L. (2011): World Tourism Organization (UNWTO) Affiliate Members AM-reports. - Technology in Tourism 1: 10.

[6] Eijgelaar, E., de Kinderen, D. (2014): Carbon offsetting: motives for participation and impacts on travel behavior. - In: Cohen, S. A., Higham, J. E. S., Peeters, P., Gössling, S. (Eds.) Understanding and governing sustainable tourism mobility: Psychological and behavioural approaches, pp. 125-143. Abingdon, UK: Routledge.

[7] Fielding, K. S., Head, B. W. (2012): Determinants of young Australians' environmental actions: the role of responsibility attributes, locus of control, knowledge and attitudes. Environmental Education Research 18: 171-186.

[8] Gössling, S. (2011): Carbon Management in Tourism: Mitigating the Impacts on Climate Change. - Abingdon, Oxon, England ; New York: Routledge. 345 pp.

[9] Guilford, J. P. (1965): Fundamental Statistics in Psychology and Education, 4th Ed. - NY: McGraw, Hill.

[10] Han, H., Hsu, L.-T. J., Lee, J.-S., Sheu, C. (2011): Are Lodging Customers Ready to Go Green? An Examination of Attitudes, Demographics, and Eco-friendly Intentions. International Journal of Hospitality Management 30(2): 345-355.

[11] Heimlich, J. E., Ardoin, N. M. (2012): Understanding behavior to understand behavior change: a literature review. - Environmental Education Research 14(3): 215-237.

[12] Huang, M. C. (2012): A Study of Potential Demand on the Mobile Application for Seniors. - Journal of Psychology Research 11(2):22-34.

[13] Kang, K.H., Stein, L., Heo, C.Y., Lee, S. (2012): Consumers' Willingness to Pay for Green Initiatives of the Hotel Industry. - International Journal of Hospitality Management 31(2): 564-572.

[14] Kerlinger, F.N. (1986): Foundations of Behavioral Research, 3rd ed. - New York: Holt, Rinehart and Winston.

[15] Kim, A. K., Airey, D., Szivas, E. (2011): The multiple assessment of interpretation effectiveness: promotion visitors' environmental attitudes and behavior. - Journal of Travel Research 50(3): 321-334. doi: $10.1177 / 0047287510362786$

[16] Lawrence, E. V. (2012): Visitation to natural areas on campus and its relation to place identity and environmentally responsible behaviors. - The Journal of Environmentally Education 43: 93-106. http://dx.doi.org/10.1080/00958964.2011.604654

[17] Lee, T. H. (2011): How recreation involvement, place attachment and conservation commitment affect environmentally responsible behavior. - Journal of Sustainable Tourism 19: 895-915.

[18] Lu, W., Stepchenkova, S. (2012): Ecotourism experiences reported online: Classification of satisfaction attributes. - Tourism Management 33(3): 702-712.

[19] Mair, J. (2011): Exploring air travellers' voluntary carbon-offsetting behaviour. - Journal of Sustainable Tourism 19: 215-230.

[20] McKercher, B., Prideaux, B., Cheung, C., Law, R. (2010): Achieving voluntary reductions in the carbon footprint of tourism and climate change. - Journal of Sustainable Tourism 18: 297-317. 
[21] Mobley, C., Vagias, W. M., DeWard, S. L. (2010): Exploring additional determinants of environmentally responsible behavior: the influence of environmental literature and environmental attitudes. - Environment and Behavior 42(4): 420-447.

[22] Neuhofer, B., Buhalis, D., Ladkin, A. (2012): Conceptualising technology enhanced destination experiences. - Journal of Destination Marketing \& Management 1(1-2): $36-46$.

[23] Nishiyama, M., Terasawa, T. (2013): Long-lasting implicit memory for unfamiliar faces revealed by an indirect recognition procedure. - Shinrigakukenkyu: The Japanese journal of psychology 83(6): 526-535.

[24] Phillips, J., Walford, N., Hockey, A., Foreman, N., Lewis, M. (2013): Older people and outdoor environments: pedestrian anxieties and barriers in the use of familiar and unfamiliar spaces. - Geoforum 47:113-124.

[25] Puhakka, R. (2011): Environmental concern and responsibility among nature tourists in Oulanka PAN Park, Finland. - Scandinavian Journal of Hospitality and Tourism 11(1): 76-96. http://dx.doi.org/10.1080/15022250.2011.532589

[26] Robeia, B. A., Greenhow, C., Burton, L. (2011): Environmental learning in online social networks: adopting environmentally responsible behaviors. - Environmental Education Research 17(4): 553-575. http://dx.doi.org/10.1080/13504622.2011.565118

[27] Shrode, F. (2012): Mobile apps for nature field guides. - Reference Reviews 26(7): 4-6. http://dx.doi.org/10.1108/09504121211270771

[28] Trochidis, K., Bigand, E. (2015): Investigation of the effect of mode and tempo on emotional responses to music using EEG power asymmetry. - Journal of Psychophysiology 27:142-148. http://dx.doi.org/10.1027/0269-8803/a000099

[29] Wang, W. Z. (2010): Influences of plant Display Design Employed with Landscape Narrative on Visitors' Behavior-a case study of Botanical Garden of National Museum of Natural Science. - Chaoyang University of Technology, Taichung, Taiwan. 